Шийка Ю., Олексів Г. Реалізація змішаного навчання в заклахах вищої освіти Канади

УДК 378.147.091.31:[37.018.4:004

DOI https://doi.org/10.24919/2308-4863/34-5-41

\begin{abstract}
Юлія ШИЙКА,
orcid.org/0000-0003-2474-0479

кандидат педагогічних наук, доцент,

дочент кафедри прикладної лінгвістики

Національного університету «Львівська політехніка»

(Львів, Україна) julia-shyika@ukr.net
\end{abstract}

Галина ОЛЕКСІВ,

orcid.org/0000-0002-8800-6217

старший викладач кафедри іноземних мов

Начіонального університету «Львівська політехніка»

(Львів, Украӥна) halyna.d.oleksiv@lpnи.иа

\title{
РЕАЛІЗАЦІЯ ЗМІШАНОГО НАВЧАННЯ В ЗАКЛАДАХ ВИЩОЇ ОСВІТИ КАНАДИ
}

\begin{abstract}
Інновачійні технології віртуального спілкування та навчання в Інтернеті створюють нові способи для викладачів та студентів взаємодіяти та ефективно навчатися. На сьогодні «ні мета, ні методи, ні населення, для якого призначена освіта, не мають жодних схожостей із тими, на яких історично базується формальне навчання» (Pond, 2002). Ці невідворотні зміни в галузі вищої освіти змущують переосмислити основні концепціі навчання та викладання. Щоб зробити иі зміни актуальними та реальними, інформаційно-комунікаційні технології повинні допомогти створити спільноти студентів, які підтримують взаємодію та співпрацю. Деякі зміни зачеплять і роль викладача. Якщзо під час традиційного аудиторного навчання викладач передає свої знання студентам, під час дистанційного навчання - виступає в ролі інструктора, то під час змішаного навчання викладач активно співпрацює зі студентами під час розроблення, сприяння та спрямування освітнього досвіду (Pond, 2002). У статті здійснено аналіз програм змішаного навчання в закладах вищої освіти Канади. Вивчено та проаналізовано наукову літературу, присвячену висвітленню проблеми змішаного навчання, його ефективносmі, якості та успішної імплементації. Встановлено, щуо змішане навчання набирає популярності, оскільки такий формат дає змогу ефективно використовувати інтернет-ресурси та сучасні комунікачійні технологї̈ для досягнення навчальних иілей. Особливої актуальності така форма навчання набула через необхідність дотримання соиіальної дистанції під час пандемії коронавірусної хвороби. У статті зазначено різницю між аудиторним, змішаним та онлайн-навчанням, а також охарактеризовано основні переваги змішаного навчання, такі як гнучкий графік навчання, ширший вибір навчального матеріалу, можливість керувати власним розкладом тошо, ш⿻о більшою мірою зачікавить студентів у вивченні матеріалу у відповідний для них час, щчо своєю чергою матиме позитивний вплив на академічну успішність.
\end{abstract}

Ключові слова: змішане навчання, заклади вищяої освіти, інформаційні технології.

Yuliia SHYIKA, orcid.org/0000-0003-2474-0479 Candidate of Pedagogical Sciences, Associate Professor at the Department of Applied Linguistics Lviv Polytechnic National University (Lviv,Ukraine) julia-shyika@ukr.net

Halyna OLEKSIV, orcid.org/0000-0002-8800-6217 Senior Lecturer at the Department of Foreign Languages Lviv Polytechnic National University (Lviv, Ukraine) halyna.d.oleksiv@lpnu.ua

\section{IMPLEMENTATION OF BLENDED LEARNING IN HIGHER EDUCATION INSTITUTIONS OF CANADA}

Innovative technologies of Internet communication and learning create new ways for teachers and students to interact and learn effectively. Today, "neither the goal, nor the methods, nor the population for which education is intended, have any similarities with those on which formal education is historically based". These inevitable changes in higher education are intended to rethink the basic concepts of teaching and learning. To make these changes relevant and real, information and communication technologies have to assist in building students communities which support interaction 
and collaboration. Some changes will affect the role of the teacher. If in traditional face-to-face education a teacher passes his knowledge to students, in distance learning he or she acts as an instructor, however in blended learning a teacher cooperates actively with students in the development and promotion of educational experience (Pond, 2002). Blended learning programs in Canadian higher education institutions have been analyzed in the article. The scientific literature devoted to the problem of blended learning, its efficiency, quality and successful implementation has been studied and analyzed. It has been concluded that blended learning is gaining popularity, as this format allows the effective use of Internet resources and modern communication technologies to achieve educational goals. This form of education has become especially relevant due to the requirement to keep social distancing during the COVID-19 pandemic. The difference between face-to-face, blended and online learning has been outlined as well as the main advantages of blended learning, such as flexible schedule, wider choice of learning material, the ability to manage personal schedule, etc. have been described.

Key words: blended learning, higher education institutions, information technology.

Постановка проблеми. Впровадження змішаного навчання поряд із традиційним аудиторним навчанням зумовлено спробою не тільки залучити іноземних студентів за допомогою сучасних інформаційних технологій. Грунтовні дослідження науковців та опитування студентів виявили позитивний ефект змішаного навчання на академічну успішність. Швидкі темпи розвитку новітніх освітніх платформ заохочують студентів брати активну участь у навчанні та зумовили застосування більш індивідуального підходу до кожного студента у процесі здобуття знань, що створює краще підгрунтя для ефективної співпраці студентів.

Аналіз досліджень. Змішане навчання та окремі його аспекти $\epsilon$ предметом педагогічних досліджень як зарубіжних, так і вітчизняних науковців. Теоретичні основи змішаного навчання досліджували: О. Бойко, Т. Задорожна, А. Стрюк, К. Торн (K. Thorne), Б. Аллан (B. Allan), Дж. Гофманн (J. Hofmann); специфіку змішаного навчання в закладах вищої освіти досліджували: Н. Кіяновська, О. Васильєва, Д. Гаррісон (D. Garrison), К. Кемпбелл (C. Campbell), A. Рахман (A. Rahman); аспекти змішаного навчання в канадських освітніх закладах досліджували: Н. Острашевський (N. Ostashewski), Р. Фердіг (R. Ferdig), К. Бонк (C. Bonk).

Мета статті - здійснити аналіз наукової літератури, присвяченої висвітленню проблеми використання змішаного навчання в закладах вищої освіти Канади.

Виклад основного матеріалу. Змішане навчання все частіше застосовується в закладах вищої освіти завдяки використанню вебтехнологій у процесі навчання та викладання. Майже всі курси вищої освіти певною мірою містять інформаційні та комунікаційні технології. Ці технології створюють нові можливості для студентів взаємодіяти зі своїми колегами, викладачами та навчальними матеріалами. Застосування інформаційно-комунікаційних технологій у вищій освіті привертає все більше уваги до теорії та практики змішаного навчання.
Змішане навчання передбачає поєднання традиційного аудиторного та онлайн-навчання 3 використанням комп'ютерних технологій. Під час такого навчання матеріали, що подаються в аудиторії та онлайн, доповнюють одне одного і спрямовані на досягнення студентами навчальних цілей. Загалом існує кілька визначень змішаного навчання. Р. Овстон з Йоркського університету (Канада) характеризують змішане навчання як навчальний процес, який частково замінює онлайн-навчання традиційними аудиторними заняттями (Owston, 2013). У своїй книзі «Змішане навчання у вищій освіті: основи, принципи та рекомендації» Р. Гаррісон та Н. Воган визначають змішане навчання як продумане поєднання аудиторного та онлайн-навчання. Такий принцип полягає в тому, що аудиторне усне спілкування та письмове спілкування в режимі онлайн оптимально інтегровані так, що їхні сильні сторони поєднуються для створення унікального навчального досвіду, що сприяє досягненню навчальних цілей (Garrison, 2008). Ч. Джуйбан з Університету Центральної Флориди - закладу вищої освіти, який вважається лідером у впровадженні змішаного навчання в Північній Америці, зазначає, що змішане навчання варто розглядати як педагогічний підхід, що поєднує ефективність і можливості соціалізації в аудиторії з технологічно розширеними можливостями активного навчання в інтернет-середовищі (Dzuiban, 2004).

Консорціум Слоун - провідна організація, яка займається інтеграцією електронного навчання у вищу освіту, - визначає змішане навчання як таке, що забезпечує 30-79 \% викладеного матеріалу онлайн (табл. 1) (Allen, 2007).

Загалом виділяють три основні причини застосування змішаного навчання (Graham, 2005):

- збільшення доступу та гнучкості;

- підвищення якості освіти;

- підвищення економічної ефективності та ефективності використання ресурсів.

К. Матеос використовує такі категорії, щоб аргументувати переваги, які онлайн-технології 
Шийка Ю., Олексів Г. Реалізація змішаного навчання в заклалах вищої освіти Канади

пропонують (а) студентам: доступ, гнучкість та нові, важливі навички для роботи в глобальному мережевому середовищі, (б) викладачам: нові навички та знання для трансформації викладацької діяльності та (в) навчальним закладам: збільшення кількості студентів, підвищення навчальних результатів та більш ефективне використання ресурсів (Matheos, 2005).

Однак існує низка факторів, яка може створювати перешкоди для запровадження змішаного навчання. Серед них вирізняють: доступ до інтернет-ресурсів, брак технічної підтримки, доступ та комфорт під час використання відповідних ресурсів, а також особисті фактори, такі як проблеми зі здоров'ям чи фізична обмеженість серед викладачів і студентів.

Одним із прикладів успішного застосування змішаного навчання $€$ Технологічний інститут Університету Онтаріо, адміністрація якого вирішила впровадити змішане навчання через пандемію. Таке навчання поєднує викладання більшості навчального матеріалу за допомогою онлайнплатформ 3 активним аудиторним навчанням, яке відбувається згідно з рекомендаціями уряду провінції Онтаріо та Міністерства охорони здоров'я. Позаяк цей заклад вищої освіти віддавна впроваджує новітні технології в навчальне середовище, університет має необхідний потенціал для адаптації до вимушених змін.

Вумовахпандеміїстуденти Технологічногоінституту Університету Онтаріо мають змогу навчатися, використовуючи (Our blended-learning approach):

- інтернет-канали, які надають доступ до онлайн-лекцій чи їхніх цифрових записів та відповідного навчального матеріалу; відповідно, розклад студентів стане максимально гнучким, що надасть їм змогу ефективно збалансувати навчальний та особистий час;

- навчальні лабораторії для проведення практичних досліджень;
- сучасні цифрові платформи, спеціальне програмне забезпечення та мобільні додатки;

- безперервну онлайн-підтримку, яка стосується академічної успішності, фінансової допомоги, психічного та фізичного здоров'я.

Західний університет Канади також пропонує студентам можливість вибрати змішане навчання, яке забезпечить їх доступом до відеолекцій у форматі $\mathrm{HD}$, віртуальних дискусій та індивідуальних занять із викладачами, що зробить навчання персоніфікованим і доступним. Окрім того, Західний університет Канади надає змогу вибирати, які навчальні предмети студенти вивчатимуть онлайн, а які - аудиторно.

Університет наголошує на таких перевагах змішаного навчання (Blended programs):

- гнучкий графік онлайн та аудиторного навчання;

- навчання з іноземними студентами, набуття досвіду міжкультурної комунікації;

- високоякісні навчальні інтернет-ресурси.

3 огляду на несприятливу епідеміологічну ситуацію Університет Торонто запровадив змішане навчання, щоб одночасно надавати студентам освітні послуги та захищати їхнє здоров'я і здоров'я науково-педагогічних працівників. Перехід на змішане навчання був ретельно спланованим улітку 2020 року, і понад 100 освітніх технологів тісно співпрацювали з викладачами, щоб забезпечити 90 \% навчальних дисциплін якісним віртуальним середовищем.

Водночас навчальні дисципліни, які вимагають безпосереднього аудиторного навчання, зокрема наукові дослідження, лабораторні роботи, групові проєкти та окремі семінари і лекції, будуть викладатися в університеті з дотриманням соціальної дистанції. Адміністрація університету погоджується, що деякі дисципліни вимагають аудиторного навчання і що деякі студенти можуть бути краще підготовлені для участі в онлайн-навчанні,

Таблиця 1

Відмінності між аудиторним, змішаним, онлайн-навчанням та навчанням із використанням інтернет-технологій

\begin{tabular}{|c|c|l|}
\hline $\begin{array}{c}\text { \% навчального матеріалу, } \\
\text { що викладається онлайн }\end{array}$ & Тип курсу & \multicolumn{1}{|c|}{ Опис курсу } \\
\hline 0 & Аудиторний & $\begin{array}{l}\text { Курс без використання інтернет-технологій - матеріал } \\
\text { подається письмово або усно. }\end{array}$ \\
\hline $1-29$ & $\begin{array}{c}\text { 3 використанням } \\
\text { інтернет-технологій }\end{array}$ & $\begin{array}{l}\text { Курс 3 використанням інтернет-технологій для допо- } \\
\text { внення аудиторного навчання. }\end{array}$ \\
\hline $30-79$ & 3мішаний & $\begin{array}{l}\text { Курс, який поєднує аудиторне та онлайн-навчання. } \\
\text { 3начна частина матеріалу подається онлайн. }\end{array}$ \\
\hline $80+$ & Онлайн & $\begin{array}{l}\text { Курс, у якому весь матеріал (або більша його частина) } \\
\text { подаєтья онлайн. Зазвичай не передбачає аудиторних } \\
\text { занять. }\end{array}$ \\
\hline
\end{tabular}


ніж інші, через доступ до технологій або житлових умов. Тому було вирішено відновити роботу бібліотек, щоб забезпечити студентів доступом до комп'ютерів, інтернету та супутніх послуг, таких як друк і сканування (U of T News).

Університет Альберти пропонує курси арабської, французької, німецької, італійської, норвезької, іспанської, шведської та української мови у форматі змішаного навчання. Ця модель поєднує аудиторне та онлайн-навчання із самостійною роботою. Зазвичай мовні курси в Університеті Альберти передбачали п'ять годин аудиторного навчання на тиждень. Нова модель забезпечує більш гнучкі графіки для студентів, скорочує аудиторне навчання до трьох годин на тиждень (як і більшість інших занять), а решта дві години передбачають онлайн-навчання та самостійну роботу (Blended Learning courses).

Університет Ватерлоо трактує змішане навчання як таке, що інтегрує аудиторне та онлайннавчання. Навчальні матеріали підбираються так, щоб онлайн-заняття доповнювали аудиторні для досягнення поставлених навчальних цілей. Понад 70 \% курсів, що пропонує заклад вищої освіти, мають онлайн-компоненти в навчальному середовищі університету.

Адміністрація Університету Ватерлоо наголошує, що змішане навчання:

- забезпечить більш гнучкий графік і дасть студентам можливість вибирати час і місце навчання;
- підвищить якість навчання, надавши змогу впроваджувати навчальні стратегії, які неможливо застосувати без відповідних технологій;

- надасть студентам змогу активно навчатися за допомогою динамічної взаємодії.

Як свідчать проведені опитування, студенти навчаються ефективніше під час змішаного навчання, порівняно з онлайновим чи аудиторним навчанням.

Змішане навчання в Університеті Валерлоо не відповідає єдиній формулі. Вивчення деяких дисциплін передбачає використання онлайн-платформ тільки для викладення лекцій, тоді як інші дисципліни використовують аудиторне навчання для лекцій і передбачають застосування онлайнсередовищ для дискусій, оцінювання чи іншої навчальної діяльності. Деякі використовують комбінацію цих двох підходів (Blended Learning).

Характер і швидкість змін у суспільстві, які пов'язані з використанням нових інформаційнокомунікаційних технологій, являють собою величезний виклик для сучасної вищої освіти. Зокрема, цей виклик полягає в застосуванні відповідних технологій для навчання. Змішане навчання забезпечує послідовний шлях уперед, який може використовувати як основа для структурних змін у суспільстві. Змішане навчання забезпечує органічне застосування комунікаційних технологій, які можуть допомогти досягнути навчальні цілі у вищій освіті.

\section{СПИСОК ВИКОРИСТАНИХ ДЖЕРЕЛ}

1. Allen I.E., Seaman J., Garrett R. Blending in: The extent and promise of blended education in the United States, 2007. 29 p.

2. Blended Learning. University of Waterloo. URL: https://uwaterloo.ca/centre-for-teaching-excellence/support/blended-learning

3. Blended Learning courses. University of Alberta. URL: https://www.ualberta.ca/modern-languages-and-cultural-studies/course-outlines/blended-learning-courses.html.

4. Blended programs. University Canada West. URL: https://www.ucanwest.ca/blended-programs.

5. Dzuiban C., Hartman J., Moskal P. Blended learning. EDUCAUSE Centre for Applied Research (ECAR) Research Bulletin. 2004 (7). P. 1-12.

6. Garrison R., Vaughan N. Blended learning in higher education: Framework, principles and guidelines. San Francisco : Josey-Bass, 2008. 272 p.

7. Graham C., Allen S., Ure, D. Benefits and challenges of blended learning environments. In M. Khosrow-Pour (Ed.), Encyclopedia of information science and technology. Hershey, PA: Idea Group, 2005. P. 253-259.

8. Matheos K., Curry, J. Online learning: Changing policies and practices. In K. Matheos and T. Carey, Advances and challenges in e-learning at Canadian research universities: Occasional papers in higher education. 2005 (12). P. 1-10.

9. Our blended-learning approach. Ontario Tech University. URL: https://ontariotechu.ca/readyforyou/blended-learning/ index.php.

10. Owston R., York D., Murtha S. Student perceptions and achievement in a university blended learning strategic initiative. The Internet and Higher Education. 2013 (18). P. 38-46.

11. Pond W. K. Distributed education in the $21^{\text {st }}$ century: Implications for quality assurance. Online Journal of Distance Learning Administration. URL: http://www.westga.edu/ distance/ojdla/summer52/pond52.html.

12. U of T News. University of Toronto. URL: https://www.utoronto.ca/news/10-things-you-need-know-about-fall-semester-u-t. 
Шийка Ю., Олексів Г. Реалізація змішаного навчання в заклалах вищої освіти Канади

\section{REFERENCES}

1. Allen I.E., Seaman J., Garrett R. Blending in: The extent and promise of blended education in the United States, 2007. 29 p.

2. Blended Learning. University of Waterloo. URL: https:/uwaterloo.ca/centre-for-teaching-excellence/support/ blended-learning.

3. Blended Learning courses. University of Alberta. URL: https://www.ualberta.ca/modern-languages-and-culturalstudies/course-outlines/blended-learning-courses.html.

4. Blended programs. University Canada West. URL: https://www.ucanwest.ca/blended-programs.

5. Dzuiban C., Hartman J., Moskal P. Blended learning. EDUCAUSE Centre for Applied Research (ECAR) Research Bulletin. 2004 (7). P. 1-12.

6. Garrison R., Vaughan N. Blended learning in higher education: Framework, principles and guidelines. San Francisco : Josey-Bass, 2008. 272 p.

7. Graham C., Allen S., Ure, D. Benefits and challenges of blended learning environments. In M. Khosrow-Pour (Ed.), Encyclopedia of information science and technology. Hershey, PA : Idea Group, 2005. P. 253-259.

8. Matheos K., Curry, J. Online learning: Changing policies and practices. In K. Matheos and T. Carey, Advances and challenges in e-learning at Canadian research universities: Occasional papers in higher education. 2005 (12). P. 1-10.

9. Our blended-learning approach. Ontario Tech University. URL: https://ontariotechu.ca/readyforyou/blended-learning/index.php.

10. Owston R., York D., Murtha S. Student perceptions and achievement in a university blended learning strategic initiative. The Internet and Higher Education. 2013 (18). P. 38-46.

11. Pond W. K. Distributed education in the $21^{\text {st }}$ century: Implications for quality assurance. Online Journal of Distance Learning Administration. URL: http://www.westga.edu/ distance/ojdla/summer52/pond52.html.

12. U of $\mathrm{T}$ News. University of Toronto. URL: https:/www.utoronto.ca/news/10-things-you-need-know-about-fallsemester-u-t. 